\section{P75 PROMOTION OF SCIENTIFIC KNOWLEDGE ON ADOLESCENT HEALTH}

${ }^{1}$ E Eisenstein*, ${ }^{2}$ I Bouzas, ${ }^{3} \mathrm{~F}$ Jannuzzi. 'Pediatrics and Adolescent Medicine, Medical School of the State University of the State of Rio de Janeiro, Rio de Janeiro, Brazil; ${ }^{2}$ Research Center for the Health Complex, University of the State of Rio de Janeiro, Rio de Janeiro, Brazili ${ }^{3}$ Center for the Study of Adolescent Health, University of the State of Rio de Janeiro, Rio de Janeiro, Brazil

\subsection{6/bmjpo-2019-RCPCH-SAHM.76}

Aims To present and discuss a summary of 15 years of scientific papers published at an official academic publication dedicated exclusively to the health and medical aspects of the population between 10 and 19 years and 11 months of age. This journal is called Adolescence \& Health and it is the only multidisciplinary Brazilian publication available also online committed to the dissemination of medical and social determinants of health during adolescence.

Methods Observational review of the 727 papers accepted for publication and their impact online, since 2010 up until April 23, 2019 with 4.576.574 online views. During the period between Sept 13, 2017 to Sept 13, 2018, the Journal's site and articles were viewed by health and other allied social professionals in 3.442 cities in Brazil, and also around 150 cities in the world. The Journal is published in Portuguese with English and Spanish abstracts available, is issued quarterly and translated online in English and Spanish, www.adolescenciaesaude.com ISSN-2177-5281.

Results The main 10 topics of importance and greater impact are: the definition criteria of adolescence; pregnancy; contraception; breast disorders; menstrual disorders; nutritional problems; alcohol, drugs and anabolic steroids use and abuse; sexually transmitted diseases and HIV/HPV; sexuality; violence and abuse. In each issue a balance between original research articles, review articles, case studies and update revisions of prevention and public policies are accepted. The Journal is part of the online ADOLEC Network with data bank on adolescents and youth sponsored by the Brazilian Ministry of Health, available at www.adolec.br. The Journal is indexed at Scopus, Latindex, IndexCopernicus, Free Medical Journals and Lilacs/BIREME and is part of the HINARI program of the World Health Organization.

Conclusion The commitment to disseminate quality science in the area of youth and adolescents health requires pertinence and constancy in the improvement of scientific channels. It is important to open opportunities for adolescent experts around the world to share their outreach community programs, clinical care and research practices. The Adolescence \& Health Journal is part of Brazilian and international efforts to spread the word adolescents, that should not be invisible as citizens, and deserve their own health rights.

\section{P76 WHEN SYMPTOMS DICTATE A YOUNG PERSONS' LIFE - AND THE IMPORTANCE OF BUILDING TRUST AND TEAM WORK IN REHABILITATION OF PATIENTS WITH COMPLEX CONDITIONS}

\footnotetext{
1,2U Gamper* ' 1J Simpson, 1,35 Moeda, 'TY Segal. 'Children and Young People's Specialist Adolescent Services, University College Hospital, London, UK; ${ }^{2}$ Department of Paediatrics and Adolescent Medicine, University Children's Hospital, Zurich, Switzerland; ${ }^{3}$ Department of Paediatrics, Hospital Beatriz Ângelo, Loures, Portugal
}

10.1136/bmjpo-2019-RCPCH-SAHM.77
Aim To illustrate how a multidisciplinary approach to young people with complex conditions can significantly improve function and quality of life.

Method Case report of a young woman, whose adolescence was spent largely bed bound due to several coexisting medical conditions including functional paralysis. Our patient was a generally unwell child. After the HPV vaccination, symptoms of fainting, weakness, pain, rashes and headaches deteriorated, leading to reduced mobility. She never fully recovered. Numerous health professionals were involved in diagnoses and management. The diagnoses established over several years included chronic fatigue syndrome, postural orthostatic tachycardia syndrome, hypermobility-type Ehler-Danlos-syndrome, mast cell disorder and skin reactions to numerous foods and medications. Aged 16, she developed lower limb paralysis after a syncopal episode which left her completely bed bound. Meanwhile functional abdominal symptoms and reduced oral intake led to severe malnutrition (BMI $14 \mathrm{~kg} / \mathrm{m}^{2}$ ) requiring parenteral nutrition. After five years, local referral to safeguarding services for suspected fabricated and induced illness resulted in a traumatic legal dispute, and the medical care was transferred to our team. Treatment objectives were identified: establishing a trusting relationship, introducing hope of recovery, reducing numbers of professionals involved, controlling symptoms, rationalising medications and rehabilitation of mobility and cognition.

Pain control was challenging occipital nerve blocks and experimental therapies, such as low dose naltrexone and ketamine infusions, were used to alleviate pain and facilitate rehabilitation. Mast cell stabilisers and antihistamines were added for symptom control. Symptoms and possible aetiologies were gently challenged whilst acknowledging the traumatic impact of previous disbelieving professionals. After initial reluctance, the role of clinical psychology and psychiatry to support and enable recovery was accepted. Indeed, whilst physically improving, overt depression with psychotic symptoms necessitated intensive involvement.

Results After one year of rehabilitation, she has remarkably improved, progressing from lying to sitting, then standing and walking with help. She is weaning TPN, and most importantly, she is more confident and hopeful for the future.

Conclusion Complex patients should be managed by a multidisciplinary team. Case-management is needed to contain symptoms and avoid overmedication. A trust-based relationship is therapeutic in itself, and symptom control might require experimental therapies.

\section{\begin{tabular}{l|l} 
P77 & GETTING IT RIGHT FOR ADOELSCENTS AND YOUNG
\end{tabular} ADULTS IN AN ACUTE ADULT HEALTH TRUST}

R Macqueen*. Young and Care and Transition Team, Sheffield Teaching Hospitals NHS FT, Sheffield, UK

\subsection{6/bmjpo-2019-RCPCH-SAHM.78}

Aim To develop developmentally appropriate healthcare for adolescents and young adults in an acute adult Trust.

Method The creation of a central adolescent, young adult and transition team within the Trust to promote the needs of adolescents and young adults and develop the elivery of developmentally appropriate healtcare within an acute adult Trust; to develop transition pathways in line with NICE (2016) guidance; to develop services to become more young person 